Rev. Bras. Saúde Prod. Anim., Salvador, v.17, n.2, p.322-330 abr./jun., 2016 http://www.rbspa.ufba.br

\title{
Características seminais e de membrana espermática em touros suplementados com tocoferol
}

\author{
Seminal characteristics and sperm membrane bulls supplemented with tocopherol
}

\author{
MARINHO, Walter Augusto dos Santos ${ }^{1 *}$; HATAMOTO-ZERVOUDAKIS, Luciana \\ $\mathrm{Keiko}^{2}$; ZERVOUDAKIS, Joanis Tilemahos'; ARGUELLO, Fernando Augusto Paes de \\ Barros $^{3}$; TSUNEDA, Bruno Hiroshi ${ }^{3}$; DUARTE JUNIOR, Moacir Ferreira ${ }^{3}$; \\ TSUNEDA, Pedro Paulo ${ }^{3}$; BARBOSA, Eleonora Araújo ${ }^{3}$
}

\author{
${ }^{1}$ Instituto Federal de Educação Ciência e Tecnologia de Mato Grosso, Campus São Vicente, Santo \\ Antônio do Leverger, Mato Grosso, Brasil. \\ ${ }^{2}$ Universidade Federal de Mato Grosso, Faculdade de Medicina Veterinária e Zootecnia, Cuiabá, Mato \\ Grosso, Brasil. \\ ${ }^{3}$ Universidade Federal de Mato Grosso, Programa de Pós-Graduação em Ciência Animal, Cuiabá, Mato \\ Grosso, Brasil. \\ *Endereço para correspondência: walter.marinho@svc.ifmt.edu.br
}

\section{RESUMO}

O trabalho teve como objetivo avaliar a integridade da membrana plasmática e qualidade seminal de touros suplementados com tocoferol. Foram utilizados 16 touros com idade média de 24 meses e peso médio de $462,2 \mathrm{~kg}$, em dois tratamentos: grupo controle (GC) e grupo suplementado com tocoferol (GE$400 \mathrm{UI}$ de tocoferol/ animal/dia) adicionados ao suplemento concentrado. Os grupos foram mantidos em pastejo com suplementação de $4,5 \mathrm{~kg} /$ animal/ dia de concentrado. A suplementação com tocoferol foi fornecida por 60 dias. Foram realizadas 4 coletas de sêmen, sendo: nos dias $0,30,60$ e 15 dias após o término da suplementação. $O$ sêmen foi coletado por eletroejaculação, aferiu-se as características físicas e morfológicas. Para avaliar a integridade de membrana utilizou-se o teste hiposmótico, coloração eosina/ nigrosina, coloração Pope e trypan blue. Os dados foram analisados através da ANOVA e do teste SNK com um nível de significância de 5\%. Foi encontrado efeito da suplementação para vigor $(\mathrm{p}=0,0183)(\mathrm{GC}=2,71 \pm 0,095$ e $\mathrm{GE}=2,23 \pm 0,16)$. Não foram encontradas diferenças $(\mathrm{p}>0,05)$ para as demais variáveis: volume, motilidade, concentração, morfologia, integridade acrossomal, viabilidade espermática e integridade de membrana. Com os resultados obtidos, nas condições experimentais do presente trabalho, conclui-se que a suplementação oral com tocoferol de 400UI/dia não apresenta melhoria sobre a qualidade seminal nem a integridade da membrana espermática de touros.

Palavras-chaves: espermatozoides, membrana celular, reprodução, touros

\section{SUMMARY}

This study had objective to evaluate the integrity of the plasma membrane and semen quality of bulls supplemented with tocopherol. Bulls were used 16 with an average age of 24 months and average weight of $462.2 \mathrm{~kg}$ in two treatments: control group (CG) and group supplemented with tocopherol (GE-400 IU of tocoferol/animal / day) added to the concentrate supplement. The groups were kept in pasture supplemented with $4.5 \mathrm{~kg} \mathrm{/} \mathrm{animal} \mathrm{/} \mathrm{day}$ concentrate. Tocopherol supplementation was provided for 60 days. 4 semen samples were carried out: on days $0,30,60$ and 15 days after the end of supplementation. Semen was collected by electroejaculation, it has measured up the physical and morphological sperm characteristics. To assess the integrity of membrane used the hyposmotic test, eosin / nigrosine, Pope and trypan blue. The experiment was conducted in a completely 
randomized design with repeated measurements over time. Data were analyzed using ANOVA and SNK test with a 5\% significance level with assistance from the SAS statistical program. It found effect of supplementation force $(\mathrm{p}=$ $0.0183)(\mathrm{CG}=2.71 \pm 0.095$ and $\mathrm{GE}=2.23 \pm$ $0.16) ;$. There were no differences $(\mathrm{p}>0.05)$ for the other variables: motility, concentration, morphology, acrosome integrity, sperm viability and membrane integrity. With the results obtained in the experimental conditions of this study, it is concluded that oral supplementation with tocopherol $400 \mathrm{IU} /$ day showed no improvement over the seminal quality or integrity of the sperm membrane Bulls.

Keywords: breeding, bulls, cell membrane, sperm

\section{INTRODUÇÃO}

A qualidade do sêmen de touros criados em condições de pastejo pode ter um grande impacto sob sua eficiência reprodutiva. Alterações da integridade espermática no epitélio seminífero podem ocorrer em decorrência da oxidação da membrana celular, com consequentes efeitos na qualidade seminal (PASQUALOTTO et al.2001; NICHI, 2003; ROMITTO, 2003). A membrana espermática é rica em ácidos graxos poliinsaturados necessários para manter a fluidez da membrana durante a fusão no momento da fertilização. Devido a isso a membrana espermática torna-se vulnerável aos danos oxidativos decorrentes da excessiva produção de ROS (espécies reativas ao oxigênio) no sêmen, causando o estresse oxidativo. A diminuição da qualidade seminal de touros à campo pode ser causado em decorrência do aumento na produção de ROS devido ao estresse térmico, prejudicando a motilidade, integridade da membrana espermática, comprometendo a capacitação, reação acrossômica, aumento na permeabilidade da membrana espermática, causando anomalias morfológicas e prejudicando a fertilidade
(CARVALHO et al., 2002; GABALDI \& WOLF, 2002; NICHI, 2003; ROMITTO, 2003). A diminuição da qualidade seminal geralmente é influenciada por fatores como ambiente, idade e dieta. Dietas contendo antioxidantes tem sido utilizada, a fim de minimizar os danos causados pelas ROS (ESKENAZI et al., 2005). A vitamina $E$ é um antioxidante lipossolúvel e tem a capacidade de impedir a propagação das reações em cadeia induzidas pelas ROS nas membranas biológicas, representando uma importante defesa contra as lesões oxidativas causadas à membrana espermática, inibindo a peroxidação lipídica dessas membranas (SMITH \& AKINBAMIJO, 2000). Objetivou-se com este trabalho avaliar características seminais e a integridade da membrana espermática de touros que foram suplementados com tocoferol por via oral.

\section{MATERIAL E MÉTODOS}

O experimento foi realizado na Fazenda Sereno - GAP, no município de Jaciara, Mato Grosso. Utilizou-se 16 touros da raça Brangus com idade média de 24 meses, e peso vivo médio de $462,2 \mathrm{~kg}$. Os animais foram distribuídos aleatoriamente em dois grupos: $\mathrm{GC}=$ Grupo controle (suplementação concentrada); $\mathrm{GE}=\mathrm{Grupo}$ vitamina $\mathrm{E}$ (suplementação com 400UI de tocoferol/ animal/ dia no concentrado). Os animais foram mantidos em piquetes de Panicum maximum cv. Mombaça. com bebedouro e cocho para fornecimento do suplemento uma vez ao dia, cujas dimensões permitiam o acesso de todos os animais simultaneamente.

O suplemento concentrado fornecido aos animais foi formulado para ganho de peso de $1 \mathrm{~kg} /$ dia e conter $21 \%$ de PB na matéria natural, era composto por: farelo de soja $(27,5 \%)$, milho moído 
Rev. Bras. Saúde Prod. Anim., Salvador, v.17, n.2, p.322-330 abr./jun., 2016 http://www.rbspa.ufba.br ISSN 15199940

$(67,25 \%)$, calcário $(1,5 \%)$, enxofre $(0,25 \%)$, uréia $(0,5 \%)$, suplemento mineral (3\%). Foram fornecidos no mesmo horário (11:00h) em quantidade equivalentes a $4,5 \mathrm{~kg} / \mathrm{animal} / \mathrm{dia}$.

Considerando-se a categoria animal e peso vivo médio dos animais, estimou-se o consumo de matéria seca (CMS) em $11,55 \mathrm{~kg}$ de $\mathrm{MS} /$ dia.

Para a estimativa da vitamina E proveniente da dieta não foi considerado quantidade proveniente na forragem, pois segundo o NRC (1996), não são encontrados valores significativos de vitamina $\mathrm{E}$ na maioria das gramíneas. Baseando-se nas estimativas calculadas na ração, observou-se que os animais do GC receberam diariamente 58 UI de vitamina $\mathrm{E}$ contidos nos alimentos. Já os animais do GE, além da vitamina $\mathrm{E}$ fornecida pelos ingredientes da ração concentrada, foram também suplementados com 400 UI de tocoferol/ animal/ dia, totalizando um fornecimento diário aos animais do GE de 458 UI de vitamina E/animal/dia.

Antes do período experimental os animais passaram por um período de adaptação de 10 dias, aos piquetes e ao concentrado. $\mathrm{O}$ experimento teve duração de 75 dias, os animais foram suplementados por um período de 60 dias. Ao final dos 60 dias continuaram recebendo o mesmo manejo, sendo fornecida a ração concentrada sem a suplementação de tocoferol por mais 15 dias.

Realizou-se 4 coletas de sêmen, sendo que a primeira coleta (D0) foi ao início da suplementação a segunda coleta com 30 dias (D30), a terceira coleta com 60 dias (D60) e a quarta coleta com 75 dias (D75). Para a coleta do sêmen os animais foram contidos em tronco apropriado e submetidos à higienização do pênis e prepúcio. Posteriormente à realização do exame clínico dos animais, realizou-se a limpeza do reto e ao mesmo tempo avaliou-se a genitália interna e em seguida o sêmen era coletado através do método de eletroejaculação, e recolhido em tubo plástico graduado em mililitros, isolado de choque térmico e da luz, previamente aquecido.

Em seguida o sêmen foi avaliado de acordo com as recomendações do Colégio Brasileiro de Reprodução Animal (CBRA, 2013), para os seguintes parâmetros: Motilidade e Vigor espermático, feitos entre lâmina $\mathrm{e}$ lamínula, previamente aquecida à $37^{\circ} \mathrm{C}$ em microscópio óptico em aumento de 100x, a motilidade foi avaliada com base na estimativa visual em porcentagem e vigor espermático como escala (0 a 5) (CBRA, 2013).

Uma alíquota de sêmen foi diluída em solução de formol salino na proporção 1:200,para avaliação da concentração espermática que foi determinada através da utilização da câmara de Neubauer e expressa em milhões de espermatozoides por mililitro $(\mathrm{mL})$. para a avaliação da morfologia espermática foi feita através de preparações úmidas, entre lâmina e lamínula, avaliando-se 200 células espermáticas com auxílio de microscopia por contraste de fase, aumento de 1000x e imersão. As alterações espermáticas foram classificadas de acordo com Barth e Oko (1989) sendo divididas em defeitos maiores (DEFMA), menores (DEFME) e totais (DEFTOT) (CBRA, 2013), que foram realizadas no Laboratório de Biotecnologia e Reprodução Animal (LABRA) da Universidade Federal de Mato Grosso. O teste hipo-osmótico (HIPO) foi realizado segundo a metodologia de Jeyendran et al. (1984) que originalmente foi desenvolvido para verificar a funcionalidade da membrana plasmática de espermatozóides humanos pode ser aplicado para avaliar sêmen de touros (CORREA \& ZAVOS, 1994). As amostras foram analisadas em microscopia com contraste de fase, aumento de $1000 \mathrm{x}$, pelo método de 
Rev. Bras. Saúde Prod. Anim., Salvador, v.17, n.2, p.322-330 abr./jun., 2016 http://www.rbspa.ufba.br ISSN 15199940

câmara úmida. Avaliou-se 200 células, sendo as células com cauda enrolada e cauda fortemente enrolada classificadas em espermatozóides normais com membrana integra (FONSECA et al., 2005).

$\mathrm{Na}$ análise da viabilidade espermática, foi utilizada a coloração de eosina e nigrosina (EOS) (WHO, 1992), onde os espermatozóides com membrana íntegra (vivos) são impermeáveis ao corante, mantendo-se incolores, e os com membrana lesionada (mortos) se coram de rosa. Foram contadas 200 células em microscópio óptico, sob imersão e aumento de 1000x. Para avaliação da integridade acrossomal, utilizou-se $\mathrm{o}$ corante simples de Pope (POPE et al., 1991) que foi avaliada em microscópio óptico, sob imersão e aumento de 1000x. Foram avaliadas 200 células classificadas em: Acrossoma íntegro, com a região acrossomal de coloração lilás; Acrossoma não íntegro: região acrossomal de coloração rosa. Foi realizada a coloração vital trypan blue/giemsa que cora os espermatozoides mortos, com membrana lesada em azul, enquanto os vivos não se coram. O Giemsa indica ausência ou presença do acrossomo, corando em roxo ou rosa escuro o acrossomo intacto (TARTAGLIONE \& RITTA, 2004). Esta técnica possibilita a visualização de quatro padrões de coloração espermática: Classe 1, espermatozóides vivos com acrossoma intacto (TRI 1); Classe 2, espermatozóides mortos com acrossoma intacto (TRI 2); Classe 3, espermatozóides vivos sem acrossoma (TRI 3); Classe 4, espermatozóides mortos sem acrossoma (TRI 4).

Foi estimado o consumo diário de vitamina $\mathrm{E}$ dos animais experimentais, e os valores da vitamina existentes na gramínea e nos ingredientes do suplemento obtidos no NRC, (2001). Deste modo, para se obter a quantidade de vitamina $\mathrm{E}$ fornecida pela dieta, estimou-se a quantidade da vitamina proveniente da ingestão de forragem e na ração concentrada (McDOWELL, 1999; NRC, 1996).

O delineamento foi inteiramente casualizado com medidas repetidas no tempo. Os dados foram analisados através da ANOVA e do teste SNK com um nível de significância de 5\% com auxilio do programa estatístico SAS (SAS, 2001).

\section{RESULTADOS E DISCUSSÃO}

Com relação ao espermiograma dos touros para a variável motilidade espermática não houve diferença entre as suplementações avaliadas $\quad(\mathrm{p}>0,05)$ (Tabela 1). Já Velásquez-Pereira et al. (1998) observaram que a motilidade espermática diminuiu $(p<0,10)$ em touros alimentados com gossipol que provoca o aumento na produção de radicais livres no sêmen, levando a peroxidação lipídica. No entanto, os touros que foram suplementados com 4000 UI de vitamina E, tiveram esse efeito negativo contraposto, demonstrando assim seu potencial antioxidante.

Corroborando com os resultados para motilidade do presente trabalho Chacur et al. (2010), também não encontraram diferença de motilidade espermática para touros suplementados por via oral durante 70 dias com produto nutracêutico comercial contendo vitamina $\mathrm{E}$ em sua composição (20ml/animal dia) correspondendo à aproximadamente 860 UI de vitamina E /animal dia. Para outras espécies animais como cães, notou-se a melhoria da motilidade com uso do tocoferol por via oral somente em animais que estavam submetidos á fatores estressantes (HATAMOTO, 2006). Com base em tais informações pressupõe que a suplementação oral de tocoferol é de 
Rev. Bras. Saúde Prod. Anim., Salvador, v.17, n.2, p.322-330 abr./jun., 2016 http://www.rbspa.ufba.br ISSN 15199940

grande importância para melhoria da motilidade espermática de animais submetidos à situações que causam aumento da peroxidação de membrana espermática.

Para a variável vigor espermático foi observado diferença entre as suplementações avaliadas $(\mathrm{p}=0,0183)$, sendo o grupo controle $(2,71 \pm 0,09)$ superior ao grupo suplementado com vitamina E $(2,23 \pm 0,16)$ (Tabela 1). Resultados que contrariam os encontrados por Xavier et al. (2008) que não observaram efeito para vigor espermático para caprinos submetidos à insulação escrotal e suplementados com selênio e vitamina $E$, somente entre coletas. Chacur et al. (2010), também não encontraram diferença de vigor espermático para touros suplementados por via oral durante 70 dias com nutracêutico contendo 860 UI de vitamina $\mathrm{E} /$ animal dia.

Tabela 1. Média \pm erro padrão e probabilidade $(\mathrm{P})$ das amostras seminais de touros Brangus não suplementados (GC) ou suplementados com vitamina E (GE)

\begin{tabular}{lccc}
\hline Variável & GC & GE & P \\
\hline Motilidade (\%) & $60,83 \pm 3,21$ & $53,41 \pm 4,60$ & 0,1855 \\
Vigor $(0-5)$ & $2,71 \pm 0,095^{\mathrm{a}}$ & $2,23 \pm 0,16 \mathrm{~b}$ & 0,0183 \\
Concentração(x10 $/ \mathrm{mL})$ & $52,71 \pm 0,095$ & $37,36 \pm 4,74$ & 0,1041 \\
TOTEJA $\left(\times 10^{6}\right)$ & $377,45 \pm 73,97$ & $295,90 \pm 62,76$ & 0,3409 \\
DEFMA (\%) & $9,46 \pm 1,60$ & $10,13 \pm 2,10$ & 0,8130 \\
DEFME(\%) & $4,33 \pm 0,62$ & $5,29 \pm 0,58$ & 0.0617 \\
DEFTOT(\%) & $13,79 \pm 1,71$ & $15,42 \pm 2,45$ & 0,6341 \\
\hline
\end{tabular}

${ }^{\mathrm{a}, \mathrm{b}}$ Médias com letras diferentes na mesma linha indicam que houve diferença pela ANAVA a 5\% de significância. total de espermatozóides do ejaculado (TOTEJA), defeitos menores (DEFME), \% de defeitos maiores (DEFMA), \% de defeitos totais (DEFTOT).

Não houve efeito da suplementação com tocoferol (Tabela 1) $(\mathrm{p}>0,05)$ para as variáveis concentração espermática, , DEFMA e DEFTOT, defeitos menores (DEFME) (Tabela 1). Esse resultado é contrário ao relatado por Velasquez Pereira et al. (1998) que verificaram diferença $(p<0,05)$ para defeitos espermáticos maiores, entre touros que receberam $(38,4 \pm 5,2)$ ou não 4000 UI de vitamina $\mathrm{E}(59,1 \pm 6,0)$. Xavier et al. (2008) também encontraram maior número de células normais pós-insulação nos animais tratados com selênio e vitamina $\mathrm{E}(65,0 \%)$ foi superior aos animais não suplementado $(26,5 \%)$. Também contrapondo os resultados do presente trabalho, Velasquez-Pereira et al. (1998) observaram que para os touros que foram suplementados com gossipol e receberam 4000 UI de vitamina $\mathrm{E}$, contrabalanceou os efeitos negativos do gossipol sobre a morfologia espermática aumentando a porcentagem de espermatozóides normais $(55,1 \pm 6,0)$. Tanto o estresse térmico quanto o efeito do gossipol podem causar danos oxidativos nas membranas espermáticas, no entanto, tais trabalhos podem indicar o efeito protetor da vitamina $\mathrm{E}$ sobre as membranas espermáticas submetidas ao estresse oxidativo, não levando à melhorias adicionais em parâmetros seminais de animais que não esteja submetido ao estresse oxidativo, o que possivelmente explica o fato do presente 
Rev. Bras. Saúde Prod. Anim., Salvador, v.17, n.2, p.322-330 abr./jun., 2016 http://www.rbspa.ufba.br ISSN 15199940

trabalho não ter apresentado diferença significativa para o parâmetro morfologia espermática.

Não houve efeito $(\mathrm{p}>0,05) \quad \mathrm{da}$ suplementação (Tabela 2), para a variáveis integridade da membrana espermática, eosina (EOS) e (HIPO), entre os tratamentos GC $(26,71 \pm 2,89)$ e GE $(26,81 \pm 3,90)$ (Tabela 2).

Não se observou efeito da suplementação com vitamina $E(p>0,05)$ para espermatozóides com acrossoma íntegro, avaliado pela coloração POPE (Tabela 2).
$\mathrm{Na}$ análise de reação acrossômica também (trypan) não foram observados efeitos $(p>0,05)$ da suplementação com tocoferol (Tabela 2). Duarte Junior et al. (2015), também não encontraram diferença nos parâmetros de integridade da membrana espermática e integridade acrossomal ao adicionar tocoferol ao meio diluidor para criopreservação do sêmen bovino. Indicando a possibilidade da suplementação com tocoferol, seja ela via oral para o sêmen fresco de bovinos, ou diretamente no meio de congelamento não apresenta melhoria em parâmetros de viabilidade espermática.

Tabela 2. Média \pm erro padrão da média (EPM) e nível de probabilidade (P) das variáveis viabilidade espermática das amostras seminais de touros Brangus não suplementados (GC) ou suplementados com vitamina $\mathrm{E}$ (GE)

\begin{tabular}{lccc}
\hline Variáveis & GC & GE & $\mathrm{P}^{*}$ \\
\hline EOS (\%) & $77,13 \pm 2,03$ & $77,70 \pm 2,89$ & 0,6060 \\
HIPO (\%) & $26,71 \pm 2,89$ & $26,81 \pm 3,90$ & 0,9488 \\
POPE (\%) & $89,78 \pm 3,83$ & $89,30 \pm 3,75$ & 0,9745 \\
TRI 1 (\%) & $91,64 \pm 1,29$ & $86,57 \pm 3,42$ & 0,1319 \\
TRI 2 (\%) & $0,51 \pm 0,10$ & $0,55 \pm 0,15$ & 0,6788 \\
TRI 3 (\%) & $5,84 \pm 0,99$ & $8,75 \pm 2,44$ & 0,2051 \\
TRI 4 (\%) & $2,04 \pm 0,68$ & $4,12 \pm 1,21$ & 0,1324 \\
\hline
\end{tabular}

$\mathrm{EOS}=$ Eosina; $\mathrm{HIPO}=$ membrana plasmática íntegra; $\mathrm{POPE}=$ acrossoma íntegro; $\mathrm{TRI}-1=$ vivos com acrossoma intacto; TRI-2= espermatozóides mortos com acrossôma intacto; TRI 3= espermatozóides vivos sem acrossoma e TRI 4= espermatozóides mortos sem acrossoma.

Segundo o NRC (1996) a exigência de vitamina $\mathrm{E}$ para bovinos de corte nas fases de crescimento e terminação varia entre 50 à 100 UI de vitamina E/dia. Dessa forma, com base na estimativa de vitamina $\mathrm{E}$ contida na dieta pode-se constatar que os níveis diários de vitamina $E$ fornecida aos animais suplementados (GE: Mombaça + Concentrado + Suplementação, 458 $\mathrm{UI} /$ tocoferol/dia), foram superiores em 4,5 vezes do nível requerido pelos animais. Dessa forma as exigências diárias de vitamina $\mathrm{E}$ de todos os animais experimentais, tanto o grupo controte (GC: Mombaça+Concentrado, $58 \mathrm{UI} /$ tocoferol/dia) quanto o GE foram atendidas, possivelmente devido a esses fatores não foram observados efeitos de tratamentos na maioria das variáveis estudadas.

É necessário maiores informações sobre a suplementação vitamínica com tocoferol e sua influência na reprodução de touros, pois verifica-se na literatura alguns trabalhos que visam avaliar a atividade antioxidante da vitamina $\mathrm{E}$ no meio diluidor para criopreservação do 
Rev. Bras. Saúde Prod. Anim., Salvador, v.17, n.2, p.322-330 abr./jun., 2016 http://www.rbspa.ufba.br ISSN 15199940

sêmen (ALMEIDA \& BALL, 2005; DUARTE JUNIOR, 2015). No entanto é importante conhecermos sua influência na viabilidade espermática de touros mantidos em rebanhos. Com base nos resultados obtidos conclui-se que a suplementação oral com 400UI de tocoferol/ animal/dia para touros, com as exigências nutricionais de vitamina $\mathrm{E}$ atendidas, não apresentou melhoria sobre a qualidade seminal nem a integridade da membrana espermática de touros.

\section{REFERÊNCIAS}

AITKEN, R.J. Molecular mechanisms regulating human sperm function.

Molecular Human Reproduction, v.3, n.3, p.169-173, 1997.

ALMEIDA, J.; BALL, B.A. Effect of $\alpha-$ tocopherol and tocopherol succinate on lipid peroxidation in equine spermatozoa.Animal Reproduction Science, v.87, p.321-337, 2005.

ALVAREZ, C.A.; MORAES, G.V. Efeitos da selenometionina e vitamina c sobre o sêmen. Sábios:Revista de Saúde e Biologia, v.1, n.1, p.42-51, 2006.

BARTH, A.D.; OKO, R.J. Abnormal morphology of bovine spermatozoa. Ames, Iwoa: Iwoa State university Press, 1989. 285p.

BROCAS, C.; RIVIERA, R.M.; PAULA-LOPES, F.F.; MACDOWELL, L.R.; CALHOUN, M.C.; STAPLES, C.R.; WILKINSON, N.S; BONING A, J.; CHENOWETH P, J.; HANSEN, P.J. Deleterious actions of gossypol on bovine spermatozoa, oocytes and embryos. Biology of Reproduction, v.57, p.901-907, 1997.
CARVALHO, O.F.; FERREIRA, J.D.J.; SILVEIRA, N.A.; FRENEAU, G.E. Efeito oxidativo do óxido nítrico e infertilidade no macho. Jornal Brasileiro de Patologia e Medicina Laboratorial, v.38, n.1, p.33-38, 2002.

CHACUR, M.G.M.; AURÉLIO, P.T.F.; OBA, E.; LAPOSY, C.B.; SCALON JUNIOR, O.; INAGUE, L.; KRONKA, S.N. Influência de um nutracêutico no sêmen, testosterona, cortisol, eritrograma e peso corpóreo em touros jovens Bos taurus indicus. Semina: Ciências

Agrárias, v.31, n.2, p.439-450, 2010.

COLÉGIO BRASILEIRO DE REPRODUÇÃO ANIMAL - CBRA. Manual para exame andrológico e avaliação de sêmen animal. 3.ed. Belo Horizonte, 2013. 104p.

CORREA, J.R.; ZAVOS, P.M. The hypoosmotic swelling test: its employment as an assay to evaluate the functional integrity of the frozen-thawed bovine sperm membrane.

Theriogenology, v.42, p.351-360, 1994.

DIAS, J.C.; ANDRADE, V.J. de; VALE FILHO, V.R. do; ALMEIDA, E.; SILVA, M. de. Biometria testicular e aspectos andrológicos de touros nelore (Bos taurus indicus), de dois e três anos de idade, criados extensivamente, Revista

Veterinária Notícias, v.13, n.2, p.31-37, 2007.

DUARTE JÚNIOR, M.F.; HATAMOTO- ZERVOUDAKIS, L.K.; ZERVOUDAKIS, J.T.; NICHI, M.; BERTOLLA, R.P.; TSUNEDA, P.P.; SENRA e SILVA, L.E.; WINGERT, F.M.; MARINHO, W.A.S. Avaliação do tocoferol no congelamento do sêmen bovino e nas taxas de prenhez após inseminação artificial em tempo fixo. Revista brasileira de Ciência Veterinária, v.22, n.2, p.114-118, 2015. 
Rev. Bras. Saúde Prod. Anim., Salvador, v.17, n.2, p.322-330 abr./jun., 2016 http://www.rbspa.ufba.br ISSN 15199940

ESKENAZI, B.; KIDD, S.A.; MARKS, A.R.; SLOTER, E.; BLOCK, G.;

WYROBEK, A.J. Antioxidant intake is associated with semen quality in healthy men. Human Reproduction, v.20, n.4, p.1006-1012, 2005.

FONSECA, J.F.; TORRES, C.A.A.; MAFFILI, V.V.; BORGES, A.M.; SANTOS, A.D.F.; RODRIGUES, M. T.; OLIVEIRA, R.F.M. The hypoosmotic swelling test in fresh goat spermatozoa. Animal Reproduction, v.2, n.2, p.139-144, 2005.

GABALDI, S.H.; WOLF, A. A Importância da termorregulação testicular na qualidade do sêmen em touros. Ciências Agrárias Saúde. FEA, v.2, n.2, p.66-70, 2002.

GARCIA, A.R. Efeitos do estresse térmico testicular e o uso da somatotropina recombinante bovina nas características seminais, integridade de membranas, função mitocondrial e estrutura da cromatina de espermatozóides de touros Simental (Bos taurus taurus). 2004. 259f. Tese (Doutorado) Universidade de São Paulo, Pirassununga.

HATAMOTO, L.K.; BAPTISTA SOBRINHO, C.A.; NICHI, M.; BARNABE, V.H.; BARNABE, R.C.; CORTADA, C.N.M. Effects of dexamethasone treatament (to mimic stress) and Vitamin E n oral supplementation on the spermiograma and on plasma spontaneous lipid peroxidation and antioxidant enzyme activies in dogs. Theriogenology, v.66, p.1610-1614, 2006.
JEYENDRAN, R.S.; VAN DER VEM, H.H.; PEREZ-PELAEZ, M.; GRAVO, B.G.; ZANEVELD, L.J.D.

Development of an assay to assess the funcional integrity of the human sperm membrane and its relationship to other semen characteristics. Journal of Reproduction and Fertitlity, v.47, p.219-228, 1984.

McDOWELL, L.R. Vitamins in animal nutrition. New York: Academic press, 1999. $486 \mathrm{p}$.

NATIONAL RESEARCH COUNCIL (NRC) Nutrient requiriments of beef cattle. 7 rev.ed. Washington D.C.:

National Academy Press, 1996. 242 p.

NATIONAL RESEARCH COUNCIL NRC. Nutrient requeriments of dairy cattle. 7.rev.ed. Washinton, D.C.:

National Academy Press, 2001. 381p.

PASQUALOTTO F. F.; SHARMA R. K.,; KOBAYASHI H..; NELSON D. R.; THOMAS JR; AGARWAL A. Oxidative Stress in Normospermic Infertile Men Undergoing Infertility Evaluation. Journal of Andrology, v.22, n.2, p.316-322, 2001.

NICHI, M. Sistemas de proteção enzimática e níveis de peroxidação espontânea dos lipídeos seminais de touros zebuínos e taurinos criados a campo na região de Dourados, MS. 2003 101p. Dissertação (Mestrado) Faculdade de Medicina Veterinária e Zootecnia, Universidade de São Paulo, São Paulo.

POPE, C.E.; ZHANG, Y.Z.; DRESSER, B.L. A simple staining method for evaluating acrossomal status of cat spermatozoa. Journal of Zoo and Wildlife Medicine, v.22, n.1, p.8795, 1991. 
Rev. Bras. Saúde Prod. Anim., Salvador, v.17, n.2, p.322-330 abr./jun., 2016 http://www.rbspa.ufba.br ISSN 15199940

REICHENBACH, H.D.; MORAES, J.C.F.; NEVES, J.P. Tecnologia do sêmen e Inseminação Artificial em Bovinos. In: GONÇALVES, P. B. D.; FIGUEIREDO, J.R.; FREITAS, V.J.F. Biotécnicas Aplicadas à Reprodução Animal. 2.ed. São Paulo: Roca, 2008. p. $57-82$.

ROMITTO, G.C. Perfil bidimensional de proteínas do plasma seminal e características ligadas ao desempenho reprodutivo de touros de corte. 2003. 192p. Dissertação (Mestrado) Universidade de São Paulo, São Paulo.

SAS. The statistical analyze systems for windows. Version 8. Cary: SAS Institute inc., 2001.

SMITH, O.B.; AKINBAMIJO, O.O. Micronutrients and reproduction in farm animals. Animal Reproduction Science, v.60-61, p.549-560, 2000.

SETCHELL B.P. The parkes lecture. Heat and the testis. Journal of Reproduction and Fertility, v.114, p.179-194, 1998.

TARTAGLIONE, C.M.; RITTA, M.N. Prognostic value of spermatological parameters as predictors of in vitro fertility of frozen-thawed bull semen. Theriogenology, v.62, p.1245-1252, 2004.

VELASQUEZ-PEREIRA, J.; CHENOWETH, P.J.; MCDOWELL, L.R.; RISCO, C.A.; STAPLES, C.A.; PRICHARD, D.; MARTIN, F.G.; CALHOUN, M.C.; WILLIAMS, S.N.; WILKINSON, N.S. Reproductive effects of feeding gossypol and vitamin E to bulls. Journal of Animal Science, v.76, p.2894-2904, 1998.
WORLD HEALTH ORGANIZATION - WHO. WHO laboratory manual for the examination of human semen and semen - cervical mucus interaction. Cambridge: Press Syndicate of the University of Cambridge, 1992. 120p.

XAVIER, G.C.; MAYMONE, A.C.M.; SOARES, P.C.; SILVA JUNIOR, V.A.; GUERRA, M.M.P. Suplementação dietética com Selênio e Vitamina E nos parâmetros seminais de caprinos induzidos à insulação escrotal. Acta Scietiarum. Animal Sciences, v.30, n. 1, p.103-111, 2008.

Data de recebimento: 07/10/2015

Data de aprovação: 18/04/2016 